\title{
Modelagem magnetométrica de ultramafitos serpentinizados do Complexo Cambaí, noroeste de Vila Nova do Sul (RS)
}

Carolina Gonçalves Leandro*, Mário Jesus Tomas Rosales, Marcos Vinícios da Silva Ferreira.

Universidade Federal do Pampa (UNIPAMPA)

Copyright 2016, SBGf - Sociedade Brasileira de Geofísica

Este texto foi preparado para a apresentação no VII Simpósio Brasileiro de Geofísica, Ouro Preto, 25 a 27 de outubro de 2016. Seu conteúdo foi revisado pelo Comitê Técnico do VII SimBGf, mas não necessariamente representa a opinião da SBGf ou de seus associados. É proibida a reprodução total ou parcial deste material para propósitos comerciais sem prévia autorização da SBGf.

\section{Resumo}

The study area has about 300 square kilometers bounded geographically by longitudes $-54.03 \mathrm{~W}-\mathrm{W}-53.90-30.24$ latitudes and the S - S - 30.32 located in Passo Rocha region, northwest of the city of Vila Nova do Sul (RS). In the southern portion of the study area geology is characterized by the presence of Neoproterozoic covers of approximately 540 Ma represented by peridotite rocks and dioritic rocks and gneiss of the formation Cambaí. In the northwestern and northern part stand out Paleozoic covers formed by siltstones, shales and sandstones represented by Palermo and Rio Bonito formations of Guatá Group of approximately $430 \mathrm{Ma}$. Data was collected from the aeromagnetic Aerogeophysical Shield of Rio Grande do Sul Project (CPRM, 2010), together with ASTER topographic data-GDEM (METI-NASA, 2008). Ground magnetic data were acquired from the execution of a survey in approximate scale of $1: 25,000$, distributed in the form of an irregular loop totaling 332 measuring stations. Magnetic susceptibility measurements were carried out "in situ" in outcrops of rock located in sectors with magnetometer signatures with significant anomalous values. The $2.5 \mathrm{D}$ modeling of magnetic data of the residual anomaly full intensity along regional geophysical profiles contributed parameters relating to the geometry of the anomalous magnetic sources associated with the presence of a vertical body in the central portion of the study area with a magnetic susceptibility value of $0: 17 \mathrm{SI}$ associated with the presence of serpentinite rocks. It was identified and outlined the top of the magnetic basement at a depth of approximately 250 meters associated with metamorphic rocks of the formation Cambai.

\section{Introdução}

A presente pesquisa utilizou o método geofísico de prospecção magnetométrica através da execução de um levantamento geofísico terrestre, conjuntamente com dados aeromagnéticos provenientes do Projeto Aerogeofísico Escudo do Rio Grande (CPRM, 2010), visando à atualização do mapeamento geofísico e geológico de rochas metamórficas de composição básica-ultrabásica na região do Passo do Rocha ao norte de Vila Nova do Sul - RS.

A área de estudo que abordou o processamento dos dados aeromagnéticos foi de aproximadamente $300 \mathrm{~km}^{2}$, delimitada geograficamente pelas latitudes $-30,17 \mathrm{~S}$ - $30,35 \mathrm{~S}$ e pelas longitudes $-54,05 \mathrm{~W}--53,89 \mathrm{~W}$, na localidade do Passo do Rocha - RS.

Com a utilização de técnicas de processamento e filtragem aplicadas aos dados aeromagnéticos, foi possível a identificação e realce de assinaturas anômalas nos mapas das diferentes transformações do campo potencial magnético, associadas à presença de rochas de composição básica existentes na área de estudo, que serviram de subsidio para orientar as aquisições de novos dados geofísicos e delimitar a área do levantamento magnetométrico terrestre.

A área de estudo que abordou a execução do levantamento magnetométrico terrestre apresenta aproximadamente $115 \mathrm{~km}^{2}$, delimitada pelas latitudes $30,26 \mathrm{~S}--30,31 \mathrm{~S}$ e pelas longitudes $-54,01 \mathrm{~W}--53,95$ W.

Como resultados finais foram confeccionados modelos geofísicos $2.5 \mathrm{D}$, ao longo de perfis regionais orientados segundo a direção NW-SE.

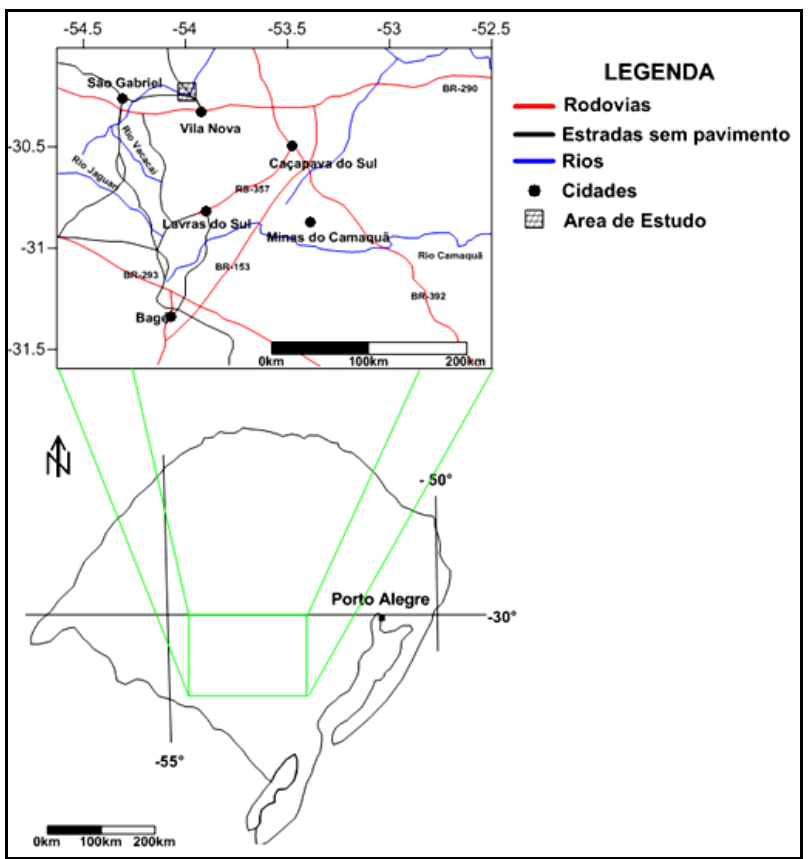

Figura 1 - Mapa de localização da área de estudo. 


\section{Arcabouço geológico}

Conforme ilustrado no mapa geológico da Figura 2, na parte sul, a geologia se caracteriza pela presença de coberturas Neoproterozóicas aproximadamente $540 \mathrm{Ma}$ representadas por metaperidotitos, gnaisses dioríticos pertencentes à formação Cambaí. Na porção noroeste e norte destacam-se coberturas paleozóicas aproximadamente $430 \mathrm{Ma}$ formadas por siltitos e folhelhos representados pela formação Rio Bonito do Grupo Guatá. Mais ao norte se destacam sedimentos atuais e subatuais do Quaternário aproximadamente 65 $\mathrm{Ma}$, representados por areias e cascalho imaturos mal selecionados, que se estendem por uma estreita faixa de nordeste a sul, e que aparecem também a oeste da área que acompanham as principais drenagens da região.

O mapa geológico da área de estudo (Fig. 2), ressalta a presença dos contornos das assinaturas magnéticas anômalas na porção central e mostra os dois perfis selecionados para a realização da modelagem magnetométrica $\left(A-A^{\prime}\right.$ e $\left.B-B^{\prime}\right)$.

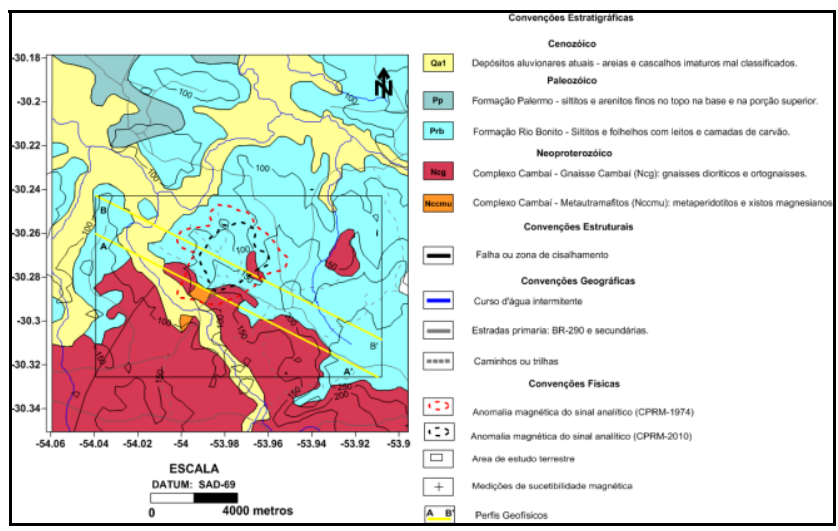

Figura 2 - Mapa mostrando o contorno das assinaturas magnéticas anômalas (ASA), conjuntamente com a geologia da área de estudo.

\section{Dados aeromagnéticos}

Foram utilizados dados aeromagnéticos provenientes do Projeto Aerogeofísico Escudo do Rio Grande do Sul, (CPRM, 2010). Inicialmente foi realizado um tratamento estatístico dos dados aeromagnéticos, e como resultado foi escolhido o método da mínima curvatura para a criação das grids que deram origem aos produtos gráficos finais. Com a utilização de técnicas de processamento e filtragem aplicadas aos citados dados, foi possível a identificação e realce de assinaturas anômalas nos mapas das diferentes transformações do campo potencial magnético.

A Figura 3 mostra o comportamento da anomalia magnética residual, que apresentou uma resolução de qualidade em termos de identificação e de realce de assinaturas anômalas magnéticas de curto comprimento de onda. Na porção central da área o comportamento da anomalia residual magnética se caracteriza pela presença de um par anômalo magnético com uma direção preferencial segundo NE-SW, apresentando um sinal positivo ao norte e um sinal negativo ao sul com valores de amplitude variando desde $-65 \mathrm{nT}$ a $+40 \mathrm{nT}$. Mais a sudoeste da porção central observa-se a presença de uma assinatura magnética anômala de menor amplitude com direção preferencial L-E, e valores de intensidade que variam de $+10 \mathrm{nT}$ ao norte até $-60 \mathrm{nT}$ ao sul. $\mathrm{Na}$ porção sul da área de estudo o comportamento do campo magnético é caracterizado pela presença de uma assinatura magnética de longo comprimento de onda provavelmente associada a fontes localizadas embasamento.

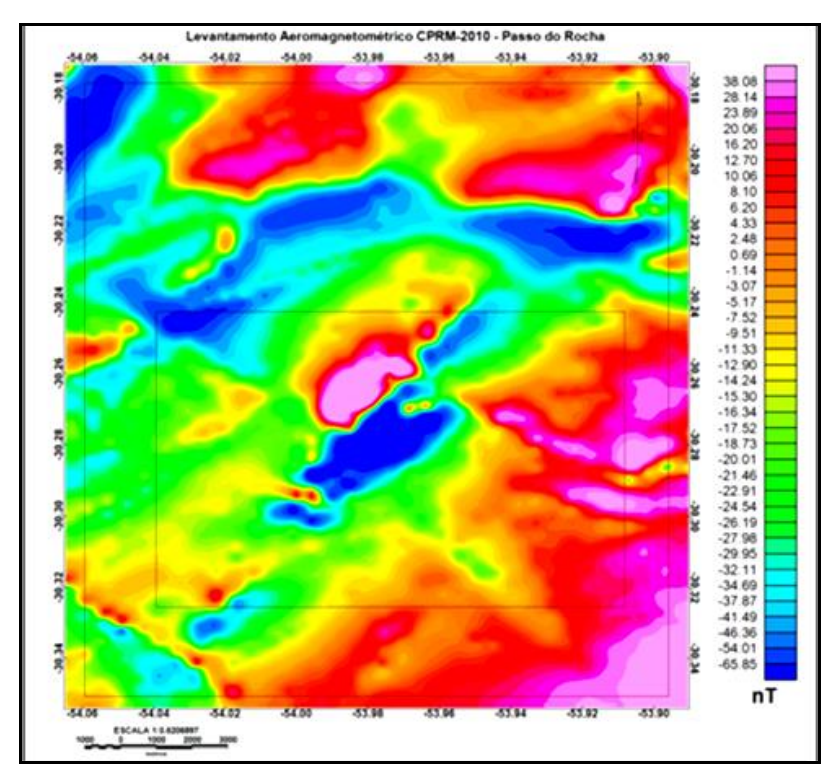

Figura 3 - Residual da Anomalia Magnética de Intensidade Total obtida dos dados aeromagnéticos (CPRM, 2010)

\section{Levantamento magnetométrico terrestre}

O levantamento magnetométrico terrestre foi realizado em escala aproximada de 1: 25.000, através de uma malha irregular totalizando 332 estações de medição. Foram realizadas medições de suscetibilidade magnética "in situ" de afloramentos de rochas próximos aos setores anômalos ressaltados através do processamento dos dados aeromagnéticos.

Os equipamentos utilizados foram dois magnetômetros de precessão de prótons GEM System Inc Canadá e um suscetibílimetro KT-10 Magnétic Sucetibility Meter Terraplus, pertencentes à UNIPAMPA. Observou-se a presença de um forte contraste entre os valores de suscetibilidade magnética das rochas serpentinizadas ( $\mathrm{K}$ médio $=25,97 \times 10^{-a}(\mathrm{SI})$ ), quando comparados aos valores das rochas encaixantes (K médio $\left.=0,111 \times 10^{-a}(\mathrm{SI})\right)$.

Sugere-se que os altos valores de suscetibilidade magnética associados às rochas serpentinizadas sejam a 
causa das anomalias do campo magnético no setor central da área de estudo.

A Figura 4 mostra o comportamento residual da anomalia magnética de intensidade total obtida a partir dos dados magnetométricos terrestres caracteriza-se, na porção central, pela presença de um par anômalo magnético com valores de amplitude que variam de $+150 \mathrm{nT}$ ao norte a $-80 \mathrm{nT}$ ao sul. Ressalta-se a alta resolução oferecida pelos dados magnetométricos terrestres, mostrando o caráter dipolar do campo magnético residual no setor central da área de estudo. $O$ fato do intervalo de amostragem no levantamento magnetométrico terrestre ser de aproximadamente 200 metros, permite obter um melhor detalhamento em termos de cobertura de pontos físicos medidos para uma melhor caracterização geofísica das assinaturas magnéticas na área de estudo. As assinaturas anômalas magnéticas de menor comprimento de onda identificadas a partir do processamento dos dados do aerolevantamento CPRM, 2010, foram ressaltadas a partir do processamento e interpretação dos dados provenientes do levantamento magnetométrico terrestre, oferecendo um melhor grau de detalhe.

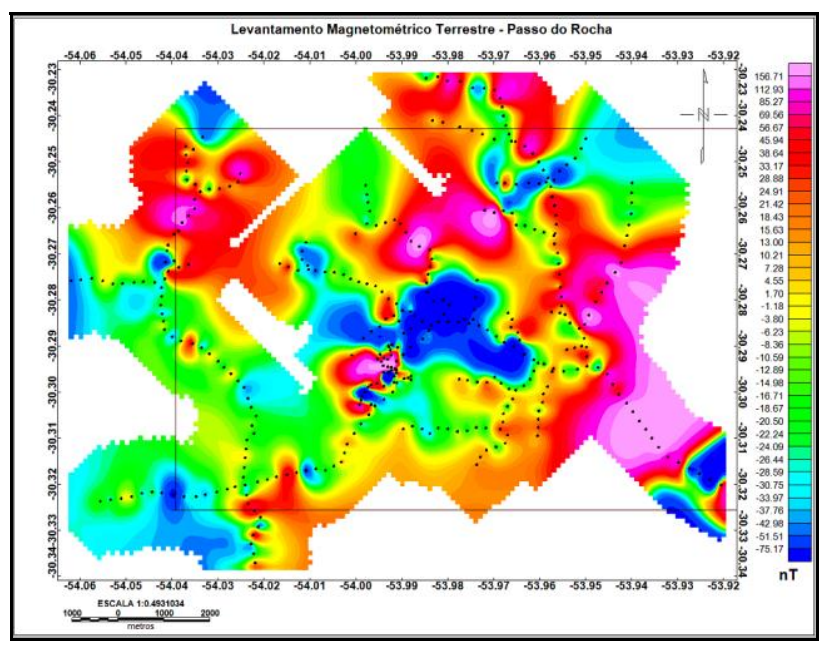

Figura 4 - Residual da anomalia magnética de intensidade total obtida dos dados magnetométricos terrestres.

\section{Modelo Digital de elevação de Terreno (DEM)}

A Figura 5 mostra o Modelo Digital de Elevação do Terreno (DEM) baseado em dados ASTER. Os dados ASTER GDEM (METI/NASA) oferecem uma resolução espacial em longitude e latitude de 1 arcsecond ( 30 metros) e uma resolução vertical de aproximadamente 714m (DEM accuracy - stdev).

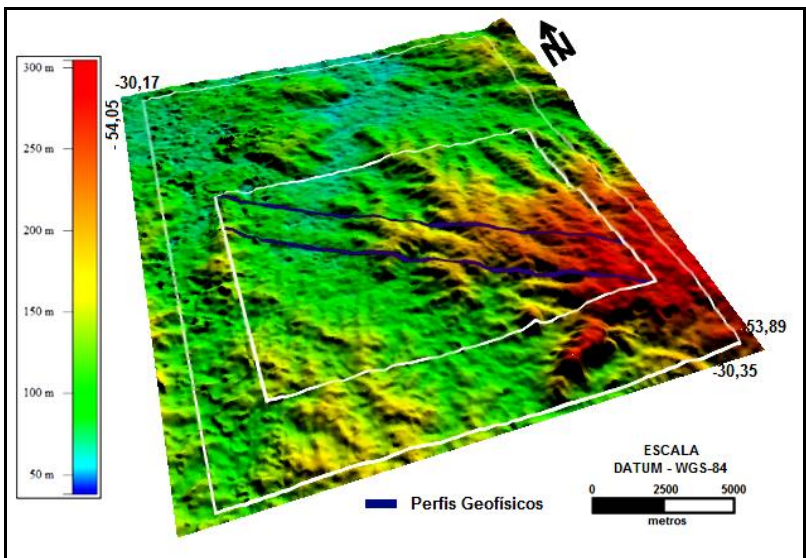

Figura 5 - Modelo digital de elevação do terreno baseado em dados topográficos ASTER-GDEM.

\section{Integração dos dados}

A Figura 6, mostra de uma maneira integrada o comportamento da anomalia magnética residual de intensidade total dos levantamentos aéreos e terrestres, o relevo topográfico baseados em dados ASTER-GDEM e as informações geológicas associadas com a suscetibilidade magnética ao longo dos Perfis A-A' e B-B' com orientação NW-SE.

\section{-Perfil A-A:}

O perfil A-A' apresentou pares anômalos magnéticos oriundos do processamento dos dados aeromagnéticos e terrestres, mantendo semelhança com relação ao formato geométrico da anomalia dipolar, isto é, a presença de um sinal positivo ao norte com uma baixa amplitude e um sinal negativo ao sul com amplitudes mais intensas. Ressaltando-se valores de amplitude mais intensos das anomalias referente aos dados terrestres se comparados com os dados aéreos.

A integração do comportamento do campo magnético residual de intensidade total, associado com o relevo topográfico e as medições de suscetibilidade, sugere que as assinaturas magnéticas anômalas estão associadas à presença de metaultramáfitos pertencentes à Formação Cambaí ( 540 Ma).

A quebra abrupta do relevo na direção SW, esta possivelmente associada à presença de falhamentos.

\section{- Perfil B-B'}

O perfil B-B' apresentou pares anômalos magnéticos oriundos do processamento dos dados aeromagnéticos e terrestres, mantendo semelhança com relação ao formato geométrico da anomalia dipolar, conforme observado no perfil A-A'.

Ressalta-se um aumento do comprimento de onda das assinaturas anômalas magnéticas com relação ao perfil $A-A^{\prime}$, o que sugere que estas respostas podem estar associadas a fontes mais profundas, isto é, a presença do prolongamento do metaultramafito em profundidade provavelmente com mergulho na direção NE. 


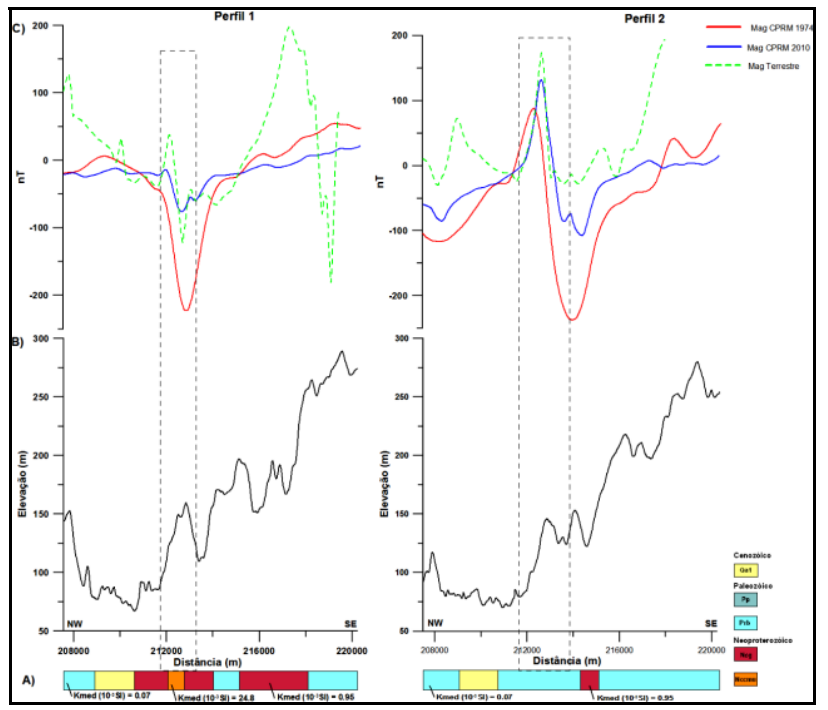

Figura 6-Gráficos do perfil A-A' e Perfil B-B'A) Informação geológica (CPRM, 2000); B) Relevo Topográfico baseado em dados de altitudes do modelo digital de elevação global (ASTER GDEM); C) Anomalia Residual do Campo Magnético de Intensidade Total.

\section{Modelo geofísico-geológico}

Os modelos geofísico-geológicos foram baseados nas interpretações qualitativas a quantitativas obtidas a partir das transformações do campo potencial.

O software utilizado para as modelagens magnetométricas foi o Mag2dc, trata-se de um software desenvolvido pela University Witwatersrand Johannesburg- South Africa, que permite a confecção de modelos geofísicos com geometria 2,5 D.

A Tabela 1 mostra algumas características técnicas do software Mag2dc.

TABELA 1 - Características técnicas do software Mag2dc

\begin{tabular}{|c|c|}
\hline \multicolumn{2}{|c|}{ Software Specifications Mag2dc } \\
\hline $\begin{array}{c}\text { Maximum number of data } \\
\text { points }\end{array}$ & 650 \\
\hline $\begin{array}{c}\text { Maximum number of } \\
\text { bodies per model }\end{array}$ & 16 \\
\hline $\begin{array}{c}\text { Maximum number of } \\
\text { corners per body }\end{array}$ & 50 \\
\hline Output supported to & ASCII, HP-GL, DXF \\
\hline
\end{tabular}

Note: Plots to any Windows supported device. Units supported : Km or m. for distance. C.G.S. or S.I. for susceptibility (Witwatersrand of University).

\section{Resultados}

Analisando o comportamento da anomalia magnética residual de intensidade total obtida a partir dos dados magnetométricos terrestres (Fig. 4), percebe-se na porção central da área de estudo a presença de duas assinaturas magnéticas anômalas, uma a sudoeste, com um menor comprimento de onda associada à presença de estruturas mais rasas ou aflorantes. A segunda assinatura anômala localizada mais ao nordeste, em um contexto sedimentar, possui um maior comprimento de onda sugerindo a presença de estruturas com um elevado contraste de suscetibilidade magnética sotopostas as estruturas sedimentares. Esse comportamento é indicativo de que a fonte anômala pode estar associada à presença de um corpo que possui um prolongamento em profundidade na direção NE.

Baseado nas informações obtidas dos mapas de Anomalia Magnética Residual de Intensidade Total, Mapa de domínios magnéticos e lineamentos estruturais identificados através do cruzamento das informações topográficas e geofísicas; as Figuras 7 e 8 mostram o modelo geofísico-gológico confeccionado para o Perfil A$A^{\prime}$ e do Perfil B-B', respectivamente.

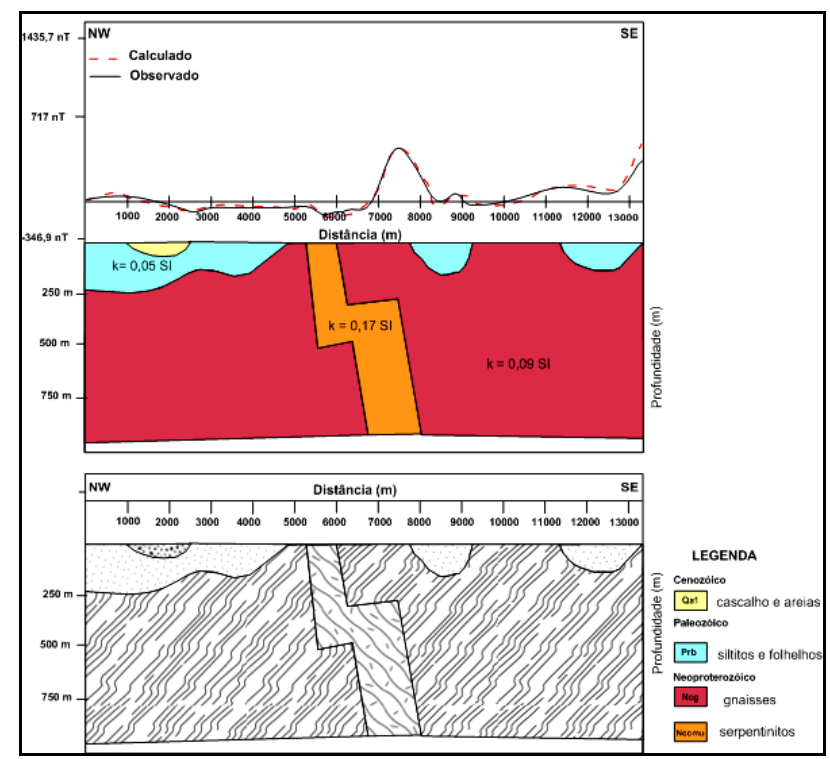

Figura 7-Modelo geofísico-geológico 2.5 D do perfil A-A' confeccionado a partir do cruzamento das informações (magnetométricas, geológicas e topográficas). 


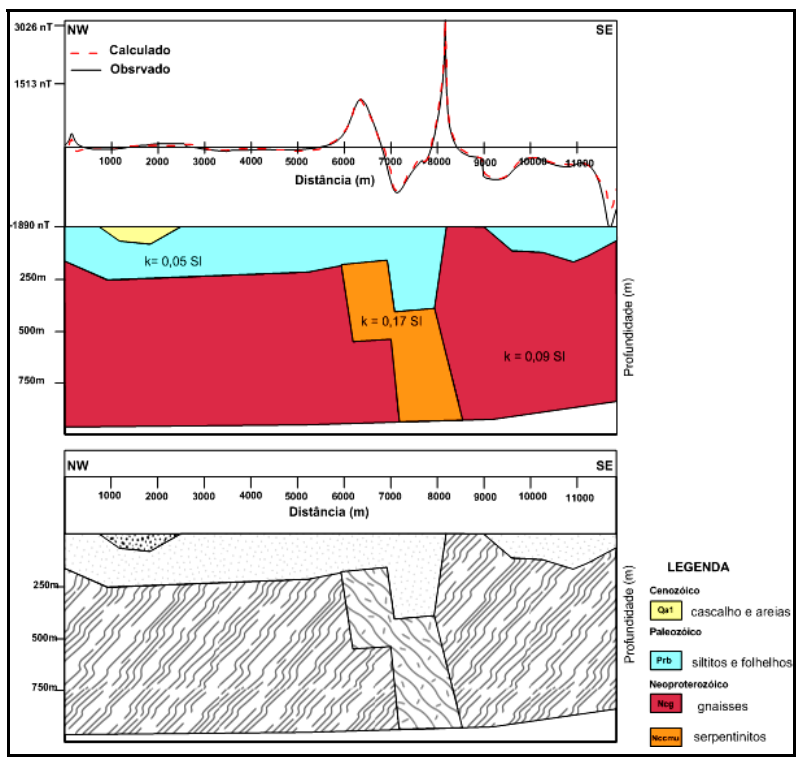

Figura 8 - Modelo geofísico-geológico 2.5 D do perfil B-B' confeccionado a partir do cruzamento das informações (magnetométricas, geológicas e topográficas).

A Figura 9 ilustra um afloramento foram realizadas medições de suscetibilidade magnética in situ. Ressaltase 0 fato de existir um patamar de valores de suscetibilidade magnética maior para o setor da área caracterizado pela presença de serpentinitos ( $\mathrm{K}$ médio: $17,3)$ se comparado com a presença de gnaisses pertencentes às rochas do embasamento metamórfico (K médio: 0,9).

A Figura 10 mostra uma proposta preliminar de modelo geológico - geofísico 3D para área de estudo com base nos parâmetros obtidos da modelagem magnetométrica 2.5 D efetuada ao longo de perfis geofísicos regionais orientados segundo a direção NW-SE.

\section{Discussão e Conclusões}

A metodologia empregada na pesquisa mostrou-se eficiente para o entendimento e esclarecimento de questões relacionadas com a geometria de feições geológicas estruturais tendo como informação o mapa geológico utilizado como base de auxilio cartográfico no posterior reconhecimento de campo.

Ressalta-se a alta resolução oferecida pelos dados magnetométricos terrestres, mostrando o caráter dipolar do campo magnético residual no setor central da área de estudo caracterizado pela presença de um sinal positivo ao nordeste e um sinal negativo ao sudeste.

O intervalo de amostragem do levantamento magnetométrico terrestre de aproximadamente 200 metros permitiu obter um detalhamento em termos de cobertura de pontos físicos medidos para a caracterização geofísica das assinaturas anômalas magnéticas com um eficiente grau de resolução.
As transformações do campo potencial magnético conjuntamente com as técnicas de filtragens utilizadas serviram para identificar e realçar assinaturas magnéticas anômalas associadas a lineamentos estruturais que apresentam direções preferências os quais poderiam estar relacionados à presença de zonas de falhamentos regional.

A modelagem 2.5 D dos dados magnéticos da anomalia residual de intensidade total ao longo de perfis geofísicos regionais aportou parâmetros referentes à geometria das fontes magnéticas anômalas associadas à presença de um corpo verticalizado na porção central da área de estudo com um valor de suscetibilidade magnética de $0.17 \mathrm{SI}$ associado à presença de rochas serpentiníticas.

Foi identificado e delineado o topo do embasamento magnético a uma profundidade de aproximadamente 250 metros associado às rochas metamórficas da Formação Cambai.

Na porção central da área de estudo foram identificados dois trends de lineamentos magnéticos com direções preferências segundo NW-SE e NE-W associados provavelmente a presença de falhas profundas que afetam o embasamento metamórfico, as quais poderiam estar relacionadas tectonicamente com processos de reativação magmática ocorridos em escala regional.

\section{Agradecimentos}

Agradecemos a UNIPAMPA por ter cedidos os equipamentos para a realização dos levantamentos geofísicos terrestres. De maneira especial se agradece a CPRM por ter disponibilizado os dados aeromagnéticos correspondentes ao Projeto Aerogeofísico Escudo do Rio Grande do Sul (CPRM, 2010).

\section{Referências}

ASTER Global DEM Validation Summary Report from http://www.gdem.aster.ersdac.or.jp/index.jsp

COOPER G. R. J. FREEWARE Mag2dc v. 2.11 for Windows. Disponível em: $<$ http://www.wits.ac.za/academic/science/geosciences/res earch/geophysics/gordoncooper/softwa.ht>

CPRM - Serviço Geológico do Brasil. Geologia e Metalogênese. FOLHA SH. 22-Y-A, Estado do Rio Grande do Sul, Escala 1:250.000. Brasília: 2000. CDROM.

GEM Systens Inc Magnetômetro de precessão de prótons. Disponível em: info@gemsys.ca

GEOSOFT. 2005. Data Processing and Analysis System for Earth Science Applications. User Guide. 
LASA PROSPECÇÕES S.A.. Projeto Aerogeofísico Escudo do Rio Grande do Sul. Relatório Final do Levantamento e Processamento dos Dados
Magnetométricos e Gamaespectrométricos. CPRM Serviço Geológico do Brasil 2010. v1 260p.

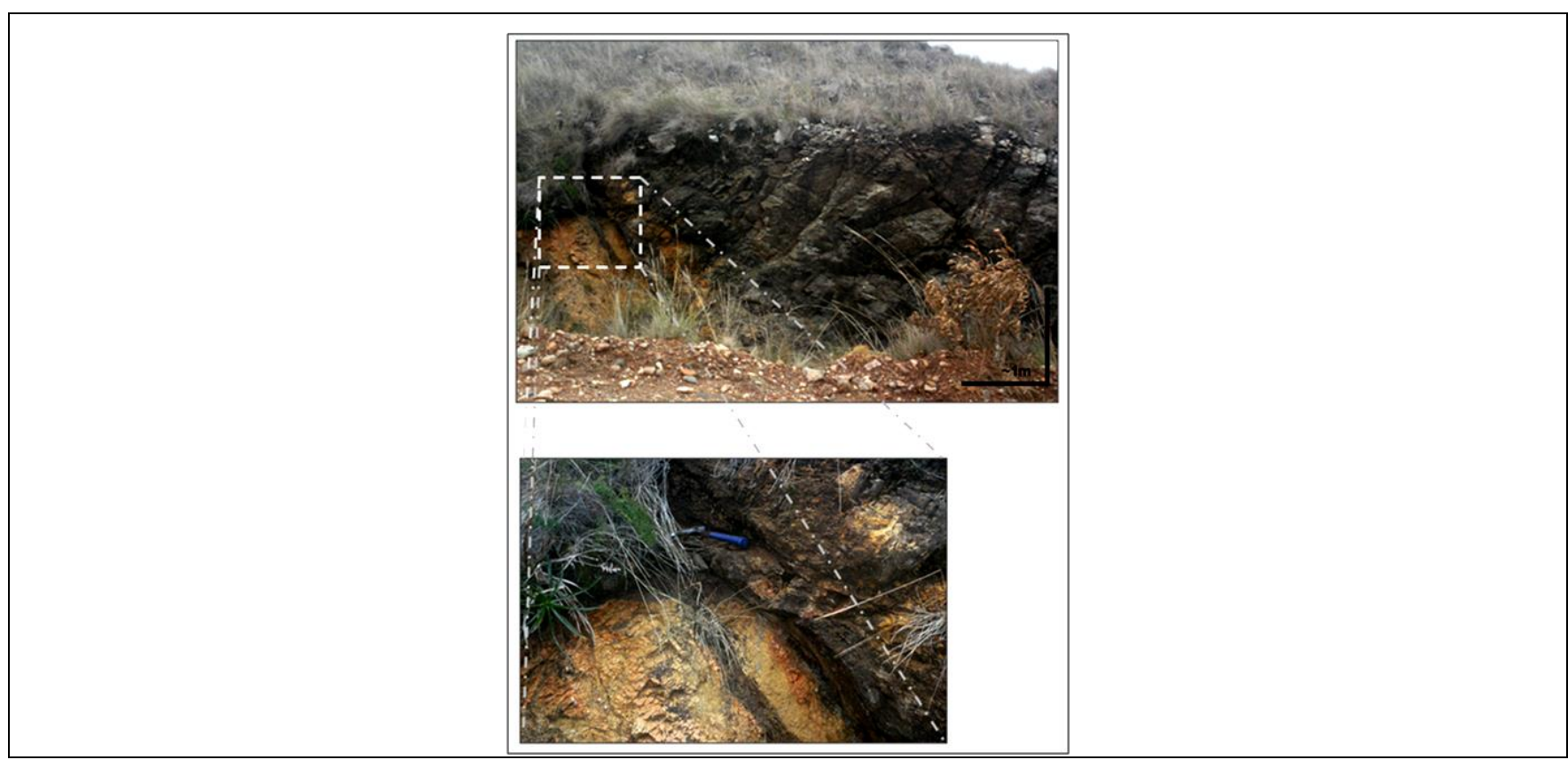

Figura 9 - Imagem do afloramento mostrando o contato entre os serpentinitos e os gnaisses do embasamento metamórfico. Posicionamento: -53,9926 W - -30,2954 S. Descricao: Serpentinito, K médio: 46,25 (10 $\left.{ }^{\mathbf{3}} \mathrm{SI}\right)$.

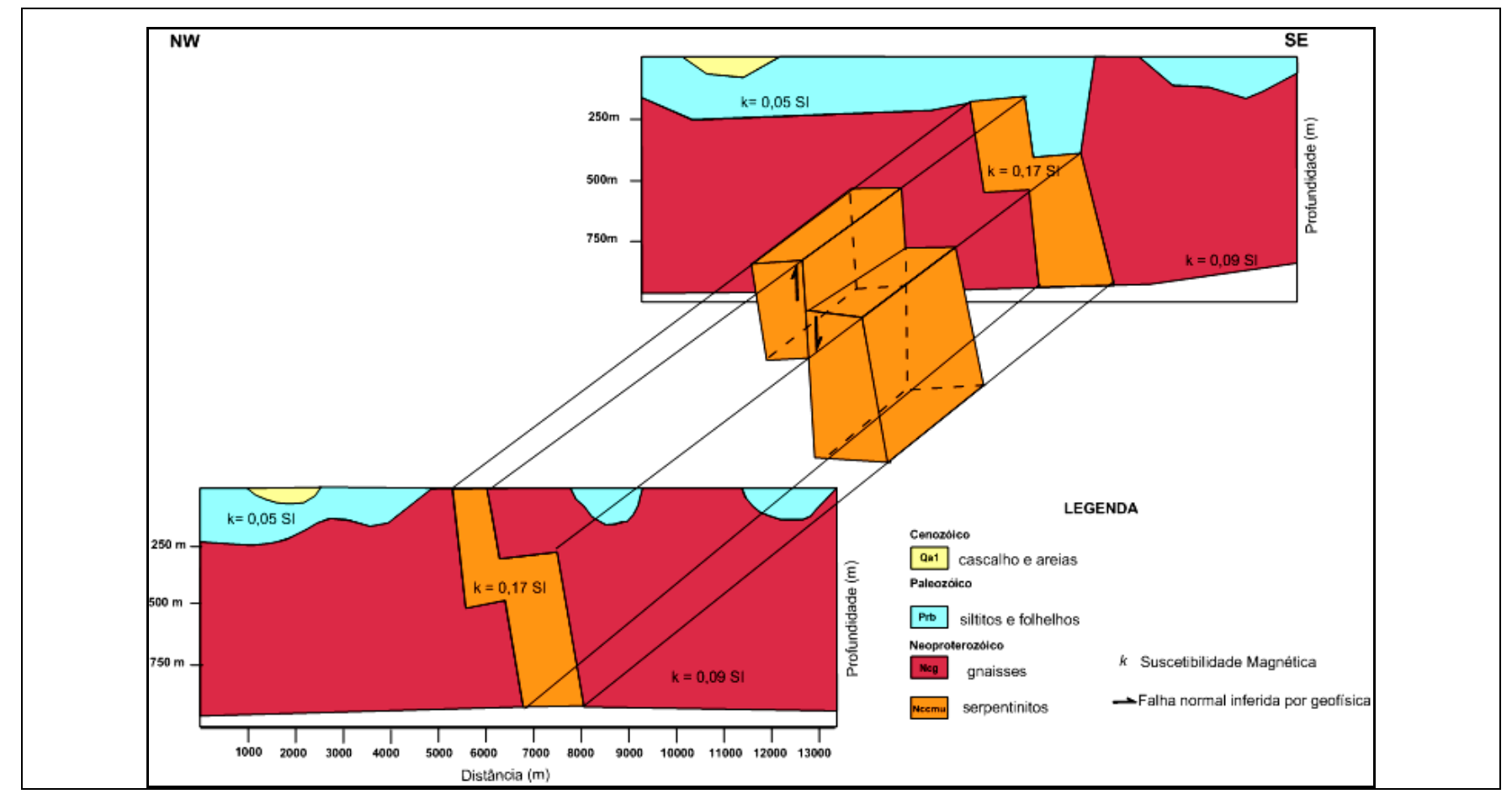

Figura 10 - Proposta de modelo geológico - geofísico 3D, obtido a partir da integração dos perfis modelado. 